\title{
Comentarios Médicos \\ El Cáncer en la agenda global: No nos olvidemos de aquellos que tienen que enfrentarse a los costos catastróficos.
}

\author{
Eduardo Payet Meza
}

El 4 de febrero es el Día Mundial del Cáncer, y aunque toca celebrar los grandes avances y logros que el mundo ha conseguido en la lucha en el Control de la enfermedad, también debemos hacer una pausa para reflexionar en un elemento clave: la catastrófica situación que muchos pacientes y sus familiares, en cualquier parte del mundo, enfrentan durante el tratamiento, una vez que recibieron el difícil diagnóstico.

Entre el $25 \%$ y el $75 \%$ de los pacientes diagnosticados con cáncer, dependiendo del país donde se encuentran, experimentan un "gasto catastrófico". Esto significa que la enfermedad no solo afecta la situación económica del paciente, sino la de toda su familia. En muchos casos destruye su futuro económico, incapacitándola para sostener otros aspectos clave como la alimentación, la educación, o la vivienda. Y todo esto solo porque un familiar ha sido diagnosticado de cáncer, requiriendo de tratamientos altamente costosos.

Ante esto, junto con pensar en ascender a nuevas escalas de tratamientos, debemos abordar las consecuencias económicas del cáncer de modo que no se convierta en un evento de ruina para miles de familias. En el Día Mundial del Cáncer, reforcemos las fórmulas para brindar soporte financiero a los pacientes, una vez que le demos el diagnóstico de cáncer, donde quieran que vivan y cualquiera sea su situación económica. Esto es posible y se puede lograr con políticas de articulación con otros sectores del estado a través de exoneraciones, facilidades para obtener créditos o participación en programas sociales.

En nuestro país, hemos estimado que para el 2019, con una población de más de 32 millones de habitantes, deberíamos atender más de 66 mil nuevos casos de cáncer y cerca de 33 mil personas fallecerán debido a él. El Seguro Integral de Salud (SIS), desde su creación y a la fecha, ha brindado cobertura oncológica gratuita a más de 94 mil pacientes de bajos recursos económicos. Esto es muy encomiable pero, como hemos visto, falta atender los efectos económicos de esta cruel enfermedad en la sociedad.

Identificando los factores de riesgo, la mayoría de casos podría ser prevenido, si dedicáramos eficientemente recursos a más y mejores acciones de promoción y prevención. Establecer diferentes niveles de atención es una prioridad, así como también desarrollar los mecanismos de accesibilidad y oportunidades de nuestra población a centros especializados en el manejo de la enfermedad y tratamientos de calidad. Hay mucho por hacer para derrotar al cáncer. Celebremos los avances pero no dejemos de trabajar por aquello que falta.

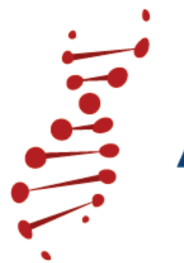

